\title{
Role of Imagery in Preoperative Evaluation of Parathyroid Lesions in Hyperparathyroidism
}

\author{
Rovena Bode ${ }^{1 *}$, Xheladin Dracini ${ }^{1}$, Etmond Celiku $^{1}$, Nikollaq Leka ${ }^{2}$ and Arben Mitrushi ${ }^{2}$ \\ ${ }^{1}$ General Surgery Department, "Mother Teresa" University Hospital Center, Albania \\ ${ }^{2}$ Radiology Department, "Mother Teresa” University Hospital Center, Albania
}

Submission: March 01, 2017; Published: March 31, 2017

*Corresponding author: Rovena Bode, General Surgery Department, “Mother Teresa” University Hospital Center, Albania, Email: rovenabode@gmail.com

\begin{abstract}
Background: Hyperparathyroidism (HPT) is an endocrine disease characterized by a hypercalcemic state due to hyper secretion of parathyroid hormone. Imaging in parathyroid disease (hyperparathyroidism) is aimed at localizing enlarged parathyroid glands after a biochemical diagnosis of hyperparathyroidism has been made. By precisely identifying the number and location of abnormal parathyroid glands, surgical parathyroidectomy can be considered and planned.
\end{abstract}

Objective: This article discusses our experience with hyperparathyroidism, from a radiological point of view, the commonly used techniques for imaging the parathyroid glands and their role in the preoperative evaluation of patients with primary hyperparathyroidism in our tertiary hospital center. The commonly used noninvasive imaging techniques: songraphy, CT, and MRI- their advantages and limitations will be discussed.

Material and methods: We have carried out a retrospective study in patients admitted for surgical treatment between January 2009 to December 2013, preoperatively diagnosed with HPT. All patients were hospitalized and prepared for surgery in the Service of Endocrinology and Nephrology where they came from. The data on patient's histories, diagnostic procedures, treatment and complications were acquired from medical reports. In order to detect and locate abnormal parathyroid tissue for preoperative localization study of diseased gland, we have used neck ultrasonography (NUS), computed axial tomography (CT) and magnetic resonance imaging (MRI).

Conclusion: The treatment of parathyroid disease is primarily surgical. However, parathyroidectomy would not be successful without accurate preoperative localization of the abnormal gland. This requires skilled radiologists at performing ultrasonography, Ct and other imaging modalities to guide the surgeon in localizing the abnormal gland(s).

Keywords: Neck sonography; CT; IRM; Hyperparathyroidism

\section{Introduction}

Primary hyperparathyroidism, whether caused by an adenoma or hyperplasia, is surgically curable with a high rate of success [1]. When performed by experienced surgeons, traditional surgical therapy-bilateral four-gland exploration is successful in more than $90 \%$ of cases [2,3]. The development of unilateral and focused surgical approaches over the past decade, however, has made it even more imperative for imaging to accurately locate abnormal parathyroid glands before surgery. With optimized preoperative mapping, the success rate of these less invasive techniques equals that of the traditional bilateral approach [4]. Experts have advocated the use of routine preoperative localization, arguing that, not all surgeons have the full experience for accurate surgical exploration; it can result in a shorter operation time; avoid the need for bilateral neck exploration, and identify rare patients with ectopic parathyroid adenomas [1,5].

Even in specialist wards, 5-10\% of operations for PHP are unsuccessful [6]. The main reasons seem to be ectopy of the parathyroid gland, numerous adenomas, multiglandular parathyroid hyperplasia, and intrathyroid location of the parathyroid $[7,8]$. The statement of the radiologist Doppman [9] is that "the only localization study needed by a patient undergoing initial parathyroid surgery is to locate an experienced parathyroid surgeon" was still valid in 1986 during the conference held by the National Institutes of Health on the diagnostics of parathyroid glands.

First of all it is very important to reduce the number of unsuccessful operations. In light of the above, imaging 
examinations of parathyroid glands should be according Table $1 \& 2$ :

Table 1: Examinations enabling identification of disease-transformed parathyroid glands examinations.

\begin{tabular}{|c|c|}
\hline S. No. & $\begin{array}{c}\text { Parathyroid Glands } \\
\text { Examinations }\end{array}$ \\
\hline 1 & USG \\
\hline 2 & CT \\
\hline 3 & MRI \\
\hline 4 & Scintigraphy \\
\hline a) & $\begin{array}{c}\text { Subtraction (thallium } \\
\text { technetium). }\end{array}$ \\
\hline b) & 'Washout' (SPECT)/Tc99m \\
sestamibi.
\end{tabular}

Table 2: Characteristics of non-invasive methods to localize diseasetransformed parathyroid glands.

\begin{tabular}{|c|c|c|c|}
\hline & USG & CT & IRM \\
\hline Sensitivity & $71-80 \%$ & $46-80 \%$ & $64-88 \%$ \\
\hline Specificity & $80-89 \%$ & $80 \%$ & $88-95 \%$ \\
\hline $\begin{array}{c}\text { Reoperation } \\
\text { sensitivity }\end{array}$ & $40 \%$ & $50-88 \%$ \\
\hline Falsely positive & $15-20 \%$ & $50 \%$ & $18 \%$ \\
\hline $\begin{array}{c}\text { Dependent on } \\
\text { Examiner skills }\end{array}$ & +++ & + & ++ \\
\hline $\begin{array}{c}\text { Exposure to } \\
\text { Radiation }\end{array}$ & No & ++ & No \\
\hline Costs & + & +++ & ++++ \\
\hline
\end{tabular}
a) Highly sensitive.
b) Highly specific.
c) As minimally invasive as possible.
d) Cost-effective.
e) Available [10].

\section{Material and Methods}

We have carried out a retrospective study in patients admitted for surgical treatment between January 2009 to December 2013, preoperatively diagnosed with HPT [1,2]. All patients were hospitalized and prepared for surgery in the Service of Endocrinology and Nephrology where they came from. The data on patient's histories, diagnostic procedures, treatment and complications were acquired from medical reports. All patients were symptomatic. The diagnosis was established biochemically by the measurement of the total calcium serum level, the serum ionized calcium level and PTH hormone level.

To support the diagnosis, radiologic examinations of the urinary system and osteo-articular system were necessary. In order to detect and locate abnormal parathyroid tissue for preoperative localization study of diseased gland, we have used neck ultrasonography (USG), computed axial tomography (CT) and magnetic resonance imaging (MRI). Scintigraphy and PET scan cannot be done at our hospitals. Calcium was measured before and after surgery, PTH hormone was monitored postoperatively.

Surgical cure was defined as the normalization of serum (ionized) calcium level and PTH levels for a period of at least 6 months after surgery. Persisting hypercalcemia or renewed of PTH within the first 6 months after surgery was considered surgery failure. A period of one year follow-up is necessary in these cases in collaboration with the endocrinology service. All patients were operated through a classical cervicotomy. Both inferior and superior parathyroid glands are identified by this approach. It continues to be the gold standard of surgical treatment. Neck ultrasonography and CT- scan were used in $100 \%$ of patients. For 4 cases with persistent HPT, neck MRI was utilized.

Correct localization or a true positive (TP) result was defined as identifying an abnormal parathyroid gland during surgery on the same location as reported by the imaging study. Abnormal parathyroid glands that were not identified by imaging technique were considered false negative (FN). Abnormalities reported by imaging that did not correspond to an abnormal parathyroid gland were considered false positive (FP). Sensitivity was calculated as $\mathrm{TP} /(\mathrm{TP}+\mathrm{FN})$ and positive predictive value was calculated as $\mathrm{TP} /(\mathrm{TP}+\mathrm{FP})$. In this analysis, the results were considered a TP if either studies correctly localized the abnormal gland. Abnormal parathyroid glands not imaged by either technique were recorded as FN, and all imaged abnormalities that did not correspond to abnormal parathyroid glands for both tests were recorded as FP.

\section{Results}

\section{Demographics}

In total, data from 14 patients were analyzed. They were $9(60 \%)$ females and $5(40 \%)$ males, with an age ranging from 34 to 68 years old. Patients belong to sporadic PHP (primary hyperparathyroidism) without any family history and SHP (secondary-renal hyperparathyroidism). Only one patient had MEN2a syndrome representing ectopic (and supernumerary) parathyroid carcinoma, medullar thyroid carcinoma and bilateral pheochromocytomas. In 8 cases there was co-existing thyroid pathology (nodular goiter) and one patient had thyroid medullar carcinoma.

\section{Preoperative evaluation}

Table 3: Symptoms in patients with HPT.

\begin{tabular}{|c|c|c|}
\hline Symptoms & $\mathbf{N r}$ & $\mathbf{\%}$ \\
\hline Uropoetic system & 12 & $85.70 \%$ \\
\hline $\begin{array}{c}\text { Osteoarticular } \\
\text { system }\end{array}$ & 9 & $64.30 \%$ \\
\hline $\begin{array}{c}\text { Gastrointestinal } \\
\text { system }\end{array}$ & 5 & $35.70 \%$ \\
\hline Neuropsychic & 13 & $71.40 \%$ \\
\hline
\end{tabular}


In our study group, the disease was manifested with symptoms from different systems (Table 3). Renal manifestations, especially urolithiasis, nefrolithiasis and their complications were present in $78.6 \%$ of cases. Patients also presented with symptoms of bone resorption, especially bone pain and fractures (64.3\%) and digestive system symptoms (35.7\%). Neuro-psychic symptoms were present in all patients. These data supported by positive imagery exams are shown in Table 4.

Table 4: Imaging in patients with HPT.

\begin{tabular}{|c|c|c|}
\hline Imaging & $\mathbf{N r}$ & $\mathbf{\%}$ \\
\hline $\begin{array}{c}\text { Osteoarticular } \\
\text { imaging }\end{array}$ & 14 & $100 \%$ \\
\hline Urinary tract imaging & 12 & $85.70 \%$ \\
\hline Bone scintigraphy & 9 & $64.30 \%$ \\
\hline
\end{tabular}

All our patients resulted with high serum levels of calcium and PTH hormone. Neck ultrasonography and CT- scan were used for $100 \%$ of patients. For 4 cases with persistent HPT, neck MRI was utilized.

Histopathologic findings included 7 eutopic solitary parathyroid adenomas, 3 ectopic parathyroid adenomas found 2 mediastinal and one intrathyroid position. One case with 3 gland parathyroid hyperplasia, and one case with parathyroid carcinoma located mediastinaly in a supernumerary gland (fifth inferior parathyroid gland). Two other cases were secondary renal hyperparathyroidism, with four gland hyperplasia (Table 5).

Table 5: Histopathologic findings.

\begin{tabular}{|c|c|c|}
\hline Histopathology & $\mathbf{N}$ & $\%$ \\
\hline Adenoma & 10 & $71.40 \%$ \\
\hline Hyperplasia & 3 & $21.40 \%$ \\
\hline Carcinoma & 1 & $7.20 \%$ \\
\hline
\end{tabular}

Table 6: Comparison between US and Ct in 14 patients with hyperparathyroidism.

\begin{tabular}{|c|c|c|c|c|c|c|}
\hline & $\begin{array}{c}\text { Positive } \\
\text { Results }\end{array}$ & TP & FP & FN & S (\%) & $\begin{array}{c}\text { PPV } \\
\text { (\%) }\end{array}$ \\
\hline USG & $1178.50 \%$ & $\begin{array}{c}8 \\
57.10 \%\end{array}$ & $\begin{array}{c}3 \\
21.40 \%\end{array}$ & $\begin{array}{c}3 \\
21.40 \%\end{array}$ & $72.80 \%$ & $72.80 \%$ \\
\hline CT & $1392.80 \%$ & $\begin{array}{c}10 \\
71.40 \%\end{array}$ & $\begin{array}{c}3 \\
21.40 \%\end{array}$ & $\begin{array}{c}1 \\
7.10 \%\end{array}$ & $91 \%$ & $77 \%$ \\
\hline
\end{tabular}

N: Number of parathyroid glands; TP: True Positive; FP: False Positive; FN: False Negative; S: Sensitivity; PPV: Positive Predictive Value

The diagnostic accuracy values for US, CT and IRM are shown in Table 6. USG was positive in $78.5 \%$ and accurately localized the pathology in $72.8 \%$, according to surgery. It has a false positive rate of $21.4 \%$ and a false negative rate of $21.4 \%$, sensitivity of $72.8 \%$ and positive predictive value of $72.8 \%$. CT results in higher values of positive results, sensitivity and positive predictive values, in comparison to USG exam. At our hospitals we cannot do parathyroid glands scintigraphy and PET-scan, for this reason we have to depend on examiner skills for the above methods.

\section{Discussion}

Ultrasonography and $99 \mathrm{mTc}$-sestamibi scintigraphy were the dominant imaging techniques for preoperative localization of parathyroid glands disease. Numerous studies comparing these techniques suggest similar sensitivities and specificities for solitary adenoma detection [11-13]. Localization accuracy is also improved when both studies are obtained preoperatively [12]. Reported sensitivities for the detection of solitary parathyroid adenomas with preoperative ultrasonography range from $72 \%$ to $89 \%$ in recent large series [10].

CT images through the neck show intense enhancement in the typical locations for parathyroid tissue in the setting of adenoma. Scanning from the skull base through the mediastinum has the additional advantage of detecting most ectopic glands. In cases of failed initial parathyroidectomy, artifacts from surgical clips placed in the neck often limit the diagnostic quality of CT. Reported sensitivities of CT range from $46 \%$ to $87 \%$ [14]. Combined studies of sonography and CT suggest that supplemental CT will detect few additional adenomas over sonography alone. Thus, CT is usually reserved for cases of failed parathyroidectomy or in cases of altered anatomy, in which CT may aid in operative planning $[15,16]$.

Recent studies have combined 99mTc-sestamibi SPECT with co-registered CT in an attempt to improve sensitivity by combining anatomic and functional information, but results from these initial studies are conflicting in their conclusions about the added usefulness of CT.

Although less commonly used for preoperative localization than sonography and CT, MRI provides similar sensitivity to other techniques in the detection of abnormal parathyroid tissue $[17,18]$. More commonly, MRI is used in patients with persistent or recurrent hyperparathyroidism, in whom it has been shown to be effective in locating remaining abnormal parathyroid tissue [19].

The T1 and T2 characteristics of abnormal parathyroid tissue are variable. The most common tissue characteristics are intermediate- to low-intensity T1 signal and high-intensity T2 signal. Less commonly, fibrosis or old hemorrhage can cause low signal intensity on T1-and T2-weighted images. Subacute hemorrhage into adenomas can cause high signal intensity on both T1-and T2-weighted images [19]. Abnormal parathyroid tissue cannot be diagnosed on MRI by signal characteristics alone because cervical lymph nodes have similar signal characteristics. Therefore, accurate MRI diagnosis depends on knowledge of the typical morphology and location of the parathyroid glands and common sites of ectopic glands.

In the current study, we compared ultrasonography with CT and MRI images. The significant positive result reported by CT $(92.8 \%)$ as well correctly predicting the surgical findings in $71.4 \%$ of patients with HPT, signifies the importance of utilizing $\mathrm{Ct}$ as well. The results were significantly higher than 
the corresponding value for US, $(78.5 \%$ positive result, and predicting the surgical findings in $57.1 \%$ of patients). The sensitivity and positive predictive value were for US $72.8 \%$ and $72.8 \%$ and for CT were $91 \%$ and $77 \%$. MRI images were used only in persistent/recurrent disease.

Among previous reports that have directly compared US and CT in patients undergoing initial parathyroid surgery, Mazzeo et al. [20] and De feo et al. [5] reported that the two methods were similar in their ability to correctly predict the surgical findings, while Casas et al. [21] and Lumachi et al. [22] found that the CT imaging was superior. In a large study encompassing US in 449 patients and SS in 700 of these patients, Cha Puis et al. [23] found that the US provides better results.

\section{Conclusion}

The treatment of parathyroid disease is primarily surgical. However, parathyroidectomy would not be successful without accurate preoperative localization of the abnormal gland. This requires skilled radiologists at performing ultrasonography, $\mathrm{Ct}$, IRM and other imaging modalities to guide the surgeon in localizing the abnormal gland(s).

\section{References}

1. Purcell GP, Dirbas FM, Jeffrey BR, Lane MJ, Desser T, et al. (1999) Parathyroid localization with high resolution ultrasound and $99 \mathrm{mTc}-$ sestamibi. Arch Surg 134(8): 824-830.

2. Udelsman R (2002) Six hundred and fifty-six consecutive explorations from primary hyperparathyroidism. Ann Surg 235(5): 665-670.

3. Tolloczko T, Chudzizski W, Nawrot I (2000) Surgery for primary hyperparathyroidism. Przegl Lek 57(Suppl 5): 101-103.

4. Haber RS, Kim CK, Inabnet WB (2002) Ultrasonography for preoperative localization of enlarged parathyroid glands in primary hyperparathyroidism: comparison with $99 \mathrm{mTc}$-sestamibi scintigraphy. Clin Endocrinol 57(2): 241-249.

5. De feo ML, Colagrande S, Tonelli A, Biagini C, Amorosi A, et al. (2000) Parathyroid glands: combination of $99 \mathrm{mTc}$-sestamibi scintigraphy and ultrasound for demonstration of parathyroid glands and nodules. Radiology 214(2): 393-402.

6. Sosa JA, Powe NR, Levine MA, Udelsman R, Zeiger MA (1998) Profile of a clinical practice: thresholds for surgery and surgical outcomes for patients with primary hyperparathyroidism-a national survey of endocrine surgeons. J Clin Endocrinol Metab 83(8): 2658-2665.

7. Grant CS, Thompson G, Farley D, van Heerden J (2005) Primary hyperparathyroidism surgical management since the introduction of minimally invasive parathyroidectomy: Mayo Clinic experience. Arch Surg 140(5): 472-478.

8. Akerstrom G, Malmaeus J, Bergstrom R (1984) Surgical anatomy of human parathyroid glands. Surgery 95(1): 14-21.

9. Doppman JL (1968) Reoperative parathyroid surgery: localization procedures, parathyroid surgery. Prog Surg 18: 1171-1175.

10. Wang CA (1976) The anatomic basis of parathyroid surgery. Ann Surg 183(3): 271-275.
11. Aleksandrides TK, Kouloubi K, Vagenakis AG, Yarmenitis S, Spyridonidis $\mathrm{T}$, et al. (2006) The value of scintigraphy and ultrasonography in the preoperative localization of parathyroid glands in patients with primary hyperparathyroidism and concomitant thyroid disease. Hormones 5(1): 42-51.

12. Henry JF, Iacobone M, Mirallie E, Deveze A, Pili S (2001) Indications and results of video-assisted parathyroidectomy by a lateral approach in patients with primary hyperparathyroidism. Surgery 130(6): 69991004

13. Jacobson SR, Van Heerden JA, Farley DR, Grant CS, Thompson GB, et al. (2004) Focused cervical exploration for primary hyperparathyroidism without intraoperative parathyroid hormone monitoring or the use of the gamma probe. World J Surg 28(11): 1127-1131.

14. Profanter C, Wetscher GJ, Gabriel M, Sauper T, Rieger M, et al. (2004) CT-MIBI image fusion: a new preoperative localization technique for primary, recurrent and persistent hyperparathyroidism. Surgery 135(2): 2157-2162.

15. Gotway MB, Higgins CB (2000) MR imaging of the thyroid and parathyroid glands. Magn Reson Imaging Clin N Am 8(1): 163-182

16. van Dalen A, Smit CP, van Vroonhoven TJ, Burger H, de Lange EE (2001) Minimally invasive surgery for solitary parathyroid adenomas in patients with primary hyperparathyroidism: role of US with supplemental CT. Radiology 220(3): 631-639.

17. Spieth ME, Gough J, Kasner DL (2002) Role of US with supplemental CT for localization of parathyroid adenomas. Radiology 223(3): 878-879.

18. Gross ND, Weissman JL, Veenker E, Cohen JI (2004) The diagnostic utility of computed tomography for preoperative localization in surgery for hyperparathyroidism. Laryngoscope 114(2): 227-231.

19. McDermott VG, Fernandez RJ, Meakem TJ, Stolpen AH, Spritzer CE, et al. (1996) Preoperative MR imaging in hyperparathyroidism: results and factors affecting parathyroid detection. AJR Am J Roentgenol 166(3): 705-710.

20. Lopez Hanninen E, Vogl TJ, Steinmuller T, Ricke J, Neuhaus P, et al. (2000) Preoperative contrast-enhanced MRI of the parathyroid glands in hyperparathyroidism. Invest Radiol 35(7): 426-430.

21. Gotway MB, Reddy GP, Webb WR, Morita ET, Clark OH, et al. (2001) Comparison between MR imaging and 99mTc MIBI scintigraphy in the evaluation of recurrent or persistent hyperparathyroidism. Radiology 218(3): 783-790.

22. Mazzeo S, Caramella D, Lencioni R, Molea N, De Liperi A, et al. (1996) Comparison among sonography, double tracer subtraction scintigraphy and double phase scintigraphy in the detection of parathyroid lesions. AJR Am J Roentgenol 166(6): 1465-1470.

23. Casas AT, Burke GJ, Sathyanarayona, Mansberger AR, Wei JP (1993) Prospective comparison of 99mTc-sestamibi/iodine-123 radionuclide scan versus high resolution ultrasonography for the preoperative localization of abnormal parathyroid glands in patients with previously unopened primary hyperparathyroidism. Am J Surg 166(4): 369-373.

24. Lumachi F, Zucchetta P, Marzela MC, Boccagni P, Angelini F, et al. (2000) Advantages of combined technetium-99m-Sestamibi scintigraphy and high resolution ultrasonography in parathyroid localization: comparative study in 91 patients with primary hyperparathyroidism. Eur J endocrinol 143(6): 755-760.

25. Chapuis Y, Fulla Y, Bonnichon P, Tarla E, Abboud B, et al. (1996) Values of ultrasonography, sestamibi scintigraphy and intraoperative measurement of 1-84 PTH for unilateral neck exploration of primary hyperparathyroidism. World J Surg 20(7): 835-839. 
This work is licensed under Creative Commons Attribution 4.0 Licens DOI: 10.19080/JTMP.2017.01.555551
Your next submission with Juniper Publishers will reach you the below assets

- Quality Editorial service

- Swift Peer Review

- Reprints availability

- E-prints Service

- Manuscript Podcast for convenient understanding

- Global attainment for your research

- Manuscript accessibility in different formats ( Pdf, E-pub, Full Text, Audio)

- Unceasing customer service

Track the below URL for one-step submission https://juniperpublishers.com/online-submission.php 